\section{Vol. 38, Issue 1, February 2011}

\section{Editorial}

5 Pathogen Reduction in Blood Products: What's Behind These Techniques?

Janetzko, K.; Bugert, P. (Mannheim)

\section{Review Articles}

8 Pathogen Reduction Technology Treatment of Platelets, Plasma and Whole Blood Using Riboflavin and UV Light

Marschner, S.; Goodrich, R.P. (Lakewood, CO)

19 Pathogen Inactivation of Platelet and Plasma Blood Components for Transfusion Using the INTERCEPT Blood System ${ }^{\text {TM }}$

Irsch, J (Ammersfoort); Lin, L (Concord, CA)

33 Development of the S-303 Pathogen Inactivation Technology for Red Blood Cell Concentrates

Henschler, R.; Seifried, E. (Frankfurt/M.); Mufti N.

(Concord, CA)

43 UVC Irradiation for Pathogen Reduction of Platelet Concentrates and Plasma Seltsam, A.; Müller, T.H. (Springe)

55 Main Properties of the THERAFLEX MB-Plasma System for Pathogen Reduction

Seghatchian, J. (London); Struff, W.G.; Reichenberg, S. (Langen)

65 The Use of Solvent/Detergent Treatment in Pathogen Reduction of Plasma

Hellstern, P. (Ludwigshafen); Solheim, B.G. (Oslo)

\section{Erratum}

71 Cross-Sectional Guidelines for Therapy with Blood Components and Plasma Derivatives (4th revised edition, 2008) - Suspension of Chapter 5 'Human Albumin'

Hoppe, J.-D. (President of the German Medical Association and of the German Medical Assembly); Scriba, P.C. (Chairman of the Scientific Advisory Board of the German Medical Association), Klüter, H. (Central Coordinator of the Standing Working Group 'Guidelines for Hemotherapy')

\section{Band 38, Heft 1, Februar 2011}

Editorial

5 Pathogenreduzierung in Blutprodukten: Was steckt hinter diesen Verfahren?

Janetzko, K.; Bugert, P. (Mannheim)

Übersichtsarbeiten

8 Pathogen-Reduction-Technology-Behandlung von Thrombozyten, Plasma und Vollblut mit Hilfe von Riboflavin und UV-Licht

Marschner, S.; Goodrich, R.P. (Lakewood, CO)

19 Pathogeninaktivierung von Thrombozyten- und Plasmablutkomponenten für die Transfusion mit Hilfe des INTERCEPT Blood System ${ }^{\text {TM }}$ Irsch, J (Ammersfoort); Lin, L (Concord, CA)

33 Entwicklung der S-303 Pathogeninaktivierungstechnologie für Erythrozytenkonzentrate Henschler, R.; Seifried, E. (Frankfurt/M.); Mufti N. (Concord, CA)

43 UVC-Bestrahlung zur Pathogenreduktion in Thrombozytenkonzentraten und Plasma Seltsam, A.; Müller, T.H. (Springe)

55 Wesentliche Eigenschaften des THERAFLEXMB-Plasma-Systems für die Pathogenreduktion Seghatchian, J. (London); Struff, W.G.; Reichenberg, S. (Langen)

65 Das Solvent/Detergens-Verfahren zur Pathogeninaktivierung in Plasma Hellstern, P. (Ludwigshafen); Solheim, B.G. (Oslo)

Erratum

71 Cross-Sectional Guidelines for Therapy with Blood Components and Plasma Derivatives (4th revised edition, 2008) - Aussetzung Chapter 5 «Human Albumin»

Hoppe, J.-D. (Präsident der Bundesärztekammer und des Deutschen Ärztetages); Scriba, P.C. (Vorsitzender des Wissenschaftlichen Beirats der Bundesärztekammer), Klüter, H. (Federführender des Ständigen Arbeitskreises «Leitlinien zur Hämotherapie»)

\section{KARGER}

Fax +49761 4520714

Information@Karger.de

www.karger.com 


\section{Vol. 38, Issue 1, February 2011}

Obituary

73 Obituary Dr. Nils Petersen

Cassens, U. (Dortmund)

75 News / Ticker

77 Meetings and Conferences

79 Guidelines for Authors

7 Imprint

\section{Band 38, Heft 1, Februar 2011}

Nachruf

73 Nachruf Dr. Nils Petersen

Cassens, U. (Dortmund)

75 News / Ticker

77 Tagungen und Kongresse

80 Hinweise für Autoren

7 Impressum 